\title{
GOETHES FAUST IN NEUER TSCHECHISCHER ÜBERSETZUNG (KOMMENTAR DES ÜBERSETZERS)
}

\author{
RADEK MALÝ / aus dem Tschechischen übersetzt von \\ JULIA MIESENBÖCK
}

\begin{abstract}
Goethe's Faust in Czech translations (translator's comment)

The study focuses on the drama Faust by J. W. Goethe and its translation specifics and demands. It traces the history of translating Faust into Czech and comments on the author's own translation approach.
\end{abstract}

Keywords: Goethe, Faust, translation

\begin{abstract}
„Kein Dichterwerk der neueren Zeit ist so oft zum Gegenstande der Erläuterung und Untersu-
\end{abstract} chung gemacht worden, wie Goethes Faust."

František Tomáš Bratránek: Erläuterungen zu Goethes Faust, 1842

Johann Wolfgang von Goethes Faust zählt zu den am häufigsten zitierten Werken der Weltliteratur. Schon allein diese Tatsache bedeutet eine Herausforderung für Übersetzer - oft wissen die Sprachmittler nicht einmal, dass sie aus dem Faust zitieren, geschweige denn sind sie sich bewusst, aus welcher Übersetzung sie zitieren. Die Frage nach den Übersetzungen dieses „superklassischen“ Werks ist gerade deshalb eine Schlüsselfrage für die tschechische Rezeption dieses Werks.

Für die Faust-Inszenierung des Regisseurs Jan Frič im Prager Stavovské divadlo (Premiere: 15. März 2018) hatte ich den Auftrag erhalten - und angenommen -, Goethes Drama zu übersetzen. Im ersten Teil dieses Aufsatzes versuche ich, den historischen Kontext zu erläutern, in dem diese zeitgenössische Übersetzung entstanden ist. Der zweite Teil widmet sich den Erklärungen der Hintergründe für die aktuelle Übersetzung. Im dritten Teil wird eine konkrete Textpassage in allen bestehenden Übersetzungen ins Tschechische vorgestellt. Das alles geschieht mit dem bescheidenen Wunsch, dass dieser Beitrag nicht gänzlich im Einklang mit seinem Motto stehen möge.

\section{Geschichte der tschechischen Faust-Übersetzungen}

Goethes Faust ist ein besonderer Text. Man denke nur an die immer wieder gestellte - und vielleicht bereits rhetorische - Frage, ob es sich überhaupt um ein „Drama“ handelt, und wenn ja, ob es sich um ein Drama handelt, das hinsichtlich des monu- 
mentalen Umfangs noch „spielbar“ ist. Die aktuelle Inszenierung des Faust im Stavovské divadlo gibt vermutlich eine weitere mögliche Antwort auf diese skeptischen Fragen. In Bezug auf die Übersetzung ist der „tschechische“ Faust allerdings dadurch besonders, dass im allgemeinen Bewusstsein eine Übersetzung existiert, die bereits kanonischen Charakter hat: Es handelt sich um die komplette und ständig verwendete Übersetzung von Otokar Fischer, 1928 erstmals publiziert.. Als würde der allgemein bekannte „Lehrsatz“ über das Altern von Übersetzungen und die Notwendigkeit einer Neuübersetzung für jede weitere Generation in diesem Fall nicht gelten. Und doch gibt es auch kritische Stimmen zu diesem Faust: „Er ist akademisch und schwer vorzutragen“, heißt es in der Anmerkung von Zdeněk Potužil und Dana Tučková, die die Faust-Übersetzung von Olga Mašková (Potužil - Tučková 2015, 297) herausgegeben haben. Vielleicht liegt der Grund für den Wunsch nach einer neuen „Generationsübersetzung“ auch in der Sehnsucht, mit dem Fluch der „Klassizität“ der Übersetzung Fischers zu brechen.

Betrachtet man jedoch die tschechische Tradition der Faust-Translate genauer, ist Fischers unerschütterliche Vorrangstellung bei weitem nicht so eindeutig. Mit seiner Übersetzung knüpfte Fischer an frühere an, die zu seiner Zeit mit Sicherheit veraltet wirkten. Die erste Übersetzung des ersten Teils des Faust stammt von Josef Jiř́i Kolár, Schauspieler, Regisseur sowie Übersetzer und Autor von Theaterstücken. Publiziert wurde sie 1863 und sie fand bereits seit 1855 Verwendung bei Inszenierungen. Kolárs Verdienst ist unter anderem heute auch deshalb beachtenswert, da er in seinem Vorwort, im Einklang mit der zeitgenössischen Wahrnehmung des Werks, erwähnt, dass der zweite Teil des Faust „viel Unverständliches und viel Unsinn“ enthalte - und dass dessen Übersetzung deshalb überflüssig sei.

Auf Kolárs Übersetzung folgte 1890 die weniger bekannte des ersten Teils der Tragödie, diesmal von František Vlček. Im selben Jahr erschien allerdings auch die Übersetzung beider Teile des Faust in Buchform - angefertigt von niemand Geringerem als Jaroslav Vrchlický, unter philologischer Beratung von Arnošt Kraus. Als vorderster Vertreter der Lumír-Schule übersetzte Vrchlický zwar technisch genau, und auch formal gibt es kaum etwas einzuwenden, doch nicht immer ist seine Übersetzung im Rahmen der Komposition des Großen und Ganzen als treu zu betrachten.

Gerade auf diesen Bereich konzentrierte sich Otokar Fischer. Im Geist moderner Übersetzungsprinzipien strebte er danach, den Text dem gegenwärtigen Lesepublikum zugänglich zu machen - ohne allzu großen und ungehörigen Respekt gegenüber dem klassischen Text. Das Ergebnis war eine lebendige und plastisch lineare Übersetzung, über welche der Germanist Vojtěch Jirát sofort nach der Fertigstellung verkündete, dass es nicht um einen „zeitweiligen Ersatz“ des Originals gehe, sondern um ein selbständiges und vollkommenes Kunstwerk. Im Gegensatz dazu, so Jirát, ließ sich Vrchlický zu sehr vom prosodischen Schema leiten, was zu Lasten der Erfassung eines höheren Sinnes des Ganzen gegangen wäre: „Vrchlický übersetzte Vers für Vers. [...] Fischer übersetzt Sätze, Bedeutungskomplexe, keine Verse, keine formalen Elemente. Er will nicht,wörtlich' sein, doch ist er treuer" (Jirát 1930, 141).

Jirát bemerkt, dass Fischer dort, wo bei Vrchlický eine Art allgemeiner „klassischer“ Stil figuriert, mit dem konkreten Stil eines einzelnen Werks arbeitet. Fischer kommentiert seinen eigenen Ansatz selbst mit folgenden Worten: 
Uns geht es heute darum, dass große, bahnbrechende Werke nicht unter dem Eindruck der Schule, in der sie erschaffen wurden, betrachtet werden, sondern dass das erfasst wird, was sie Neues, Mutiges brachten; [...] es geht deshalb darum, dass die Zeichen, durch die es [das Werk] sich hervortat, in der Übersetzung deutlicher sind als jene, durch die es sich in eine bestehende Tradition einordnete (Fischer 1983, 270).

Mit anderen Worten: Als Übersetzer hebt Fischer jene Momente des Werks hervor, deren Stil kennzeichnend ist, die den Gesamteindruck des Lesers oder Zuschauers intensivieren und ihm den Weg zu einem gesamtheitlichen Klang weisen sollen.

Als hätte Fischer einen versteckten Imperativ in die Welt gesetzt, und Scheu vor einer derart monumentalen übersetzerischen Handlung erzeugt. Vom Ende der 1960er Jahre datiert eine adaptive Übersetzung des ersten Teils und von Auszügen des zweiten Teils, Sie wurde von Jaroslav Bílý angefertigt, Übersetzer und Dramaturg des Divadlo na Vinohradech. Diese Übersetzung erschien zwar nicht in gedruckter Form, kam aber 1970 in der Inszenierung von Luboš Pistorius auf die Bühne.

Auch für die Übersetzerin Olga Mašková war Goethes Text eine Herausforderung. Für ihre Übersetzung des ersten Teils des Faust hatte sie bereits einen Vertrag mit dem Verlag Odeon unterzeichnet, der jedoch später durch den Verlag im Zuge der Restriktionen der sog. ,Normalisierung' (der Wiederherstellung autoritärer politischer Verhältnisse nach der Niederschlagung des Prager Frühlings ab 1968) aufgelöst wurde. Maškovás Übersetzung zeichnet sich - vereinfacht gesagt - durch zeitgenössische Sprache und Betonung der Musikalität der Verse aus. Die Übersetzung wurde zusammen mit einer dramaturgischen Einlage der Germanistin Růžena Grebeníčková 1984 bei einer Inszenierung im Divadlo na okraji unter der Regie von Zdeněk Potužil verwendet. Für diese Inszenierung hatte Olga Mašková in den Jahren 1983-1984 auf Anweisung des Regieteams auch Fragmente des zweiten Teils des Faust übertragen. In Buchform erschien diese Übersetzung 2015. Wie die Herausgeber Zdeněk Potužil und Dana Tučková anmerken, gestaltete sich die Herausgabe durch das Fehlen einer autorisierten Form als sehr schwierig.

Als Otomar Krejča im Jahr 1997 den Faust im Prager Národní divadlo inszenierte, lud er seinen langjährigen Mitarbeiter, den Dramaturgen, Dramatiker und Übersetzer Karel Kraus ein. Dieser übersetzte keineswegs den kompletten Text, dennoch ist im Programmheft zur Inszenierung zu lesen: „Dramaturgie und Inszenierungsbearbeitung von Otomar Krejča." Sie basiert auf dem ersten Teil des Faust, beinhaltet jedoch auch Abschnitte des zweiten Teils. Diese Übersetzung orientiert sich stark am Theater, beinhaltet verschiedene Aktualisierungen der Handlung und ist mit der Inszenierung des Regisseurs Krejča verbunden. Vladimír Just unterzieht die Übersetzung sowie das gesamte Inszenierungskonzept einer verhältnismäßig harschen, jedoch überzeugenden Kritik, unter anderem mit der Bemerkung: „Es ist ein altes Problem bei Übersetzungen, oft auch ein Paradox, wenn ältere Übersetzungen (beispielsweise jene von Kolár) in einigen Einzelheiten aktueller klingen als die Mehrheit der darauffolgenden." (Just 2014, 55)

Zur Zeit existiert noch eine weitere, sogar komplette Übersetzung beider Teile des Faust. Sie stammt von dem Chemieprofessor Petr Bouř (der erste Teil aus dem Jahr 2004, der zweite von 2015), der sich selbst dazu bekennt, dass es sich - unter Berücksichtigung der Verständlichkeit für das gegenwärtige Lesepublikum - nicht um eine wörtliche Übersetzung handele und dass darin beispielsweise die humoristische Seite des Texts betont 
sei (Bouř 2016). Mit der Übersetzung Bouřs, die bisher nicht inszeniert wurde, kann man sich leicht vertraut machen, denn sie ist auf der Internetseite doktorfaust.cz frei zugänglich. Gerade die Tatsache, dass dieser Text bisher nicht auf der Bühne zu erleben war, ist wahrscheinlich der Grund dafür, dass er in der ansonsten sehr gründlichen und inspirierenden Monographie Faust jako stav zadlužení (2014; dt. „Faust als Zustand der Verschuldung") des Theaterwissenschaftlers Vladimír Just nicht besprochen wurde.

Zuletzt sei noch ein Hilfsmittel genannt, das für jeden tschechischen „Faustologen“ von unbezahlbarem Wert ist: das populärwissenschaftliche Werk Kniha o Faustovi (dt. „Das Buch über Faust“), erschienen im Jahr 1982. Erwähnenswert ist hier der Beitrag von Jindřich Pokorný (der unter anderem auch den Urfaust übertragen hat) in Form einer Übersetzung einiger wesentlicher Teile des Faust mit ausführlichen Kommentaren.

\section{Die Entstehungsgeschichte der aktuellen tschechischen Übersetzung}

Es ist also offensichtlich, dass man sich heutzutage aus einem reichhaltigen Fundus an Faust-Übersetzungen bedienen kann, wenn man den Text für ein zeitgenössisches Publikum auf die Bühnen bringen will. Es ist nicht nötig, nach der sprachlich tatsächlich alternden Übersetzung zu greifen. Trotzdem entschied man sich, für die Inszenierung im Stavovské divadlo eine neue Übersetzung in Auftrag zu geben und wandte sich dabei an einen Übersetzer, der nicht aus dem Theaterumfeld stammt: Meine Erfahrungen mit dem Theater basieren in erster Linie auf den Übersetzungen oder Adaptierungen von Opernlibretti, außerdem bin ich Autor und Co-Autor von Drehbüchern für Kinderstücke und Hörspiele. Allerdings hatte man sich damit an einen Übersetzer - und Dichter - gewandt, der eine Vorliebe für gebundene Sprache und Form hegt, wie sie heute am Theater bei weitem nicht mehr üblich ist. Deshalb fasste ich den Entschluss, dass gerade die Beibehaltung der Form ein wichtiges Prinzip der Neuübersetzung sein soll.

Angesichts der Tatsache, dass es sich beim Faust um ein bedeutendes Werk handelt und die Übersetzung einen anspruchsvollen Auftrag darstellt - hatte ich für die Inszenierung zunächst andere Übersetzungen vorgeschlagen, die meines Erachtens gut geeignet waren. Es wurde jedoch immer deutlicher, dass Faust in der Regie von Jan Frič auf solch markante Weise interpretiert wird, dass es sich um eine individuelle Lesart dieses vielschichtigen Textes handelt. Nach meinen anfänglichen Versuchen, den Faust so zu übersetzten, als hätte ich es mit einem dramatischen Gedicht zu tun - d. h. gemäß meinen Erfahrungen beim Übersetzen deutschsprachiger Gedichte - verwarf ich zunächst die Idee einer vollständigen literarischen Übersetzung. Während der Regisseur seine Vorstellungen entwickelte, stellte sich heraus, dass eine Adaptierung von Goethes Originaltext seinen Visionen besser entsprechen würde.

In diesem Moment wurde mir klar, dass gerade dies der richtige Weg war: Wenn beide Teile des Faust in zeitnaher Sprache in einer ambitionierten Inszenierung auf die Bühne kommen und dabei keine wesentlichen Szenen weggelassen werden sollen, bleibt als Möglichkeit nur eine adaptierende Übersetzung, die auf das Maß dieser Inszenierung zugeschnitten ist. Ich entschied mich, die Befürchtungen zu ignorieren, dass „meine“ Übersetzung mit den früheren verglichen werden würde, denn es würde so oder so 
untersucht werden, wie ich mit dieser oder jener bei Fischer oder Mašková bekannten und wichtigen Stelle umgegangen bin - dies ist übrigens bekannt durch den Aufsatz von Jiří Stromšík Poznámky k novějším překladi̊m Fausta (dt. „Anmerkungen zu den neueren Übersetzungen des Faust“), wo es unter anderem heißt: „Der Nachteil der späteren Übersetzung liegt im Druck (oder der bewussten Bemühung), alles anders zu sagen. Während der Vorgänger eine bestimmte Stelle optimal übertrug, führt dies bei dem Nachfolger oft zu einer schlechteren Lösung oder einer problematischen ,Verbesserung ““ (Stromšík 1998, 54).

Mit dem Text bin ich freier als sonst bei Lyrikübersetzungen vorgegangen. Ich habe also den Faust aus dem Blickwinkel des Regisseurs Jan Frič und der Dramaturgen Marta Ljubková und Jan Tošovský übertragen. Wesentlich waren Handlung, Inhalt und der Klang ganzer Repliken und Szenen, und nicht die einzelnen Verse. All dies, obwohl ich mir Mühe gab, Goethes Texts treu zu bleiben - die Aktualisierung sollte sich schließlich in der szenischen Darbietung ausdrücken, und nicht vorrangig durch den Text gestützt werden.

Der gesamte Prozess war spannend und stellenweise geradezu dramatisch. Als Übersetzer war ich in der klassischen Rolle des Dieners, doch diente ich nicht so sehr dem Originaltext von Goethe, sondern den späteren Inszenierungen. - Das bedeutete, der Vision des Autors im Ganzen zu vertrauen, denn nicht einmal die Chronologie der einzelnen Szenen wurde im Prozess des Übersetzens beibehalten. Ich habe eher sparsam übersetzt - eingedenk des Ausmaßes des „Textmaterials“ und des Willens, beide Teile des Faust aufzuführen. Aufmerksame Leser oder Zuschauer würden, wenn sie die Übersetzung mit dem Original verglichen, schnell feststellen, dass bestimmte Passagen gekürzt wurden und einzelne Verse nicht dem Original entsprechen. Aus diesen Gründen hat der Inszenierungstext in der Form, wie er uns vorliegt, keine literarischen Ambitionen. Ich betrachte ihn eher als eine Art Libretto, einen Schnittpunkt, an dem der Schaffensgeist Goethes und des Regieteams aufeinandertreffen, zu dem ich mich bekenne.

\section{3. Übersetzungsbeispiele}

Den gewählten Zugang möchte ich anhand einer bekannten und aus dem Blickwinkel des Übersetzers faszinierenden Replik aus der Szene im Studierzimmer zeigen, einer Szene, in der Doktor Faust selbst mit einer Übersetzung kämpft, in diesem Fall sogar mit der Übersetzung der Heiligen Schrift - eine Tätigkeit, mit der er seinen „Durst nach Erkenntnis“ stillt. Ich stelle diese Passage in allen zugänglichen Übersetzungen ins Tschechische vor, chronologisch geordnet und ohne weiteren Kommentar:

Geschrieben steht: „Im Anfang war das Wort!“

Hier stock ich schon! Wer hilft mir weiter fort?

Ich kann das Wort so hoch unmöglich schätzen,

Ich muß es anders übersetzen,

Wenn ich vom Geiste recht erleuchtet bin.

Geschrieben steht: Im Anfang war der Sinn.

Bedenke wohl die erste Zeile, 
Daß deine Feder sich nicht übereile!

Ist es der Sinn, der alles wirkt und schafft?

Es sollte stehn: Im Anfang war die Kraft!

Doch, auch indem ich dieses niederschreibe,

Schon warnt mich was, daß ich dabei nicht bleibe.

Mir hilft der Geist! Auf einmal seh ich Rat

Und schreibe getrost: Im Anfang war die Tat! (Goethe 2014, 41)

Josef Jiří Kolár:

Zde psáno: „Na počátku slovo bylo!“

Již váznu! Aj, co potom zbylo?

Na nejvýš slovo nelze vážit,

ját musím lépe to rozvážit,

pravý-li mne ovládá domysl.

Jet’ psána: byl z počátku pomysl.

Stůj! Nepřekvap se v prvním řádku,

sic uchýlíš se od pořádku.

Což rozmysl zde tvoří všecka díla?

Ba státi má: z počátku byla síla!

Však, an to právě píši, tajný hlas

mne varuje, bych to hned smazal zas.

Pomáhej duchu! Jsemtě z ducha syn,

a směle píši: Bylt na počátku čin. (Goethe 1863,44$)$

František Vlček:

Tu psáno: „Slovo bylo na počátku“!

A váznu juž! Kdo pomůže mi dál?

Neb chci-li se tu vyhnout zmatku,

nelzet', bych slovo překládal,

jen dost-li osvícen jsem ve své duši.

$S$ počátku rozum byl, tak psáti sluší.

Však dobře rozvaž svých tu slov,

at brk se neukvapí vnov!

Což rozumem-li všecko budováno?

Bud’ „na počátku byla síla“ psáno.

Juž opět cosi pisatele

varuje ustat na řádku.

Mně duch pomůže! Nyní směle

napíšu: „Čin byl s počátku“! (Goethe 1890, 40-41)

Jaroslav Vrchlický:

„Z počátku bylo slovo“ - kdos tu psal.

Zde váznu již! Kdo pomůže mi dál?

Tak slovo nemohu vysoko cenit, zde musím $v$ překladu to změnit, duch právě mým-li zjevuje se snům.

Zde psáno jest: „Byl na počátku um.“

Však rozvaž dobře první ŕádku, než přehmátne se péro bez pořádku! 
Zda um to, jenž vše působí a tká?

Zpočátku síla byla, stát zde má!

Však sotva že zas tato píšu slova,

bych nepsal jich, cos varuje mne znova.

Duch pomáhá mi! Zřejmýt jeho kyn

a pišu již klidně: „Z počátku byl čin!“ (Goethe 1927, 39)

Otokar Fischer:

Zde: „Na počátku bylo slovo!“ čtu.

Ale jak dále? Nesnáz je hned tu.

Nelze mi slovo přec tak v úctě míti,

musím to jinak přeložiti;

ačli že duch mě řádně osvítil,

stojí tu: Pojem na počátku byl.

Dobře si rozvaž první řádku,

neukvapuj se na počátku!

Že vznikala by z pojmu všechna díla?

Má stati: Na počátku byla síla!

Leč ještě jsem to ani nenapsal,

a cos mě nutká, abych hledal dál.

A náhle, osvícen, zrrím do hlubin.

Já napíšu: Byl na počátku čin! (Goethe 1957, 47)

Olga Mašková:

Je psáno: Na počátku bylo slovo!

Hned úkol pro umění překladatelovo.

Znamená tolik slovo samo o sobě?

Víc výrazů mám v zásobě,

jestli už duch dost osvítil mou mysl.

Je přesnější: Byl na počátku smysl.

Nesmím své pero pustit $\mathrm{z}$ otěží,

na první větě přece nejvíc záleží.

Má smysl moc, jež všechno vytvořila?

$\mathrm{Ne}$, už vím: Na počátku byla síla!

Jak pero píše, něco říká mu,

že nevyhmátlo jádro významu.

Duch stojí při mně! Ted' už chápu čím

text vystihnu: Byl na počátku čin! (Goethe 2015, 64-65)

Jindřich Pokorný:

Čtu: „Na počátku bylo slovo.“ - Dál.

Ale jak dál? Snad abych přezkoumal,

zda nepřikládám př́liš váhy slovu.

Co dělat? - ... přeložím to znovu,

s pomocí ducha, jeho světlých sil.

„Na počátku byl... zrrejmě... rozum. Byl?

Je rozum podnět vskutku nejvyšší?

Nikoliv, síla! Tak to napíši!

Ale už zase váhám. $\mathrm{Ne}$ ? Či ano? 
Patrně má být ještě jinak psáno.

S pomocí ducha, díky za pokyn

už píši, že byl na počátku čin! (Grebeníčková 1982, 84)

Karel Kraus:

Stojí tu: „Na počátku bylo slovo!“

A už jsem v koncích! Kdo poví, jak dál?

Slovu tak veliký se význam přikládá?

$\mathrm{Ne}$, nikdy! Jinak bych to přeložil -

vždyt duch mě vede světlem svým.

Je psáno: Na počátku smysl byl.

To potom vše je dílem smyslu?

$\mathrm{Ne}$, síla byla na počátku!, má tam stát.

Už píšu - Co mi říká: nespěchat?

$S$ pomocí ducha najednou to vím!

Takhle to je: Byl na počátku čin! (Goethe 1997, 181-182)

Petr Bouř:

„Na začátku bylo slovo!“ Hmm, jako by se mi zdálo,

že jedno slovo je na všechno trochu málo.

Abych to tak moh' přeložit

musel by mi to někdo doložit.

Ted' nevím, jestli ze mě nemluví líh,

ale já bych napsal „Na počátku byl hřích.“

No, je to jak bába uprostřed náledí,

do knihy světa mi to moc nesedí.

Hřích že by vše hnal, jen taková chyba milá

Šoupneme tam: Na počátku byla síla!

Ale to je zas trochu moc odtažité,

a pro smrtelníky př́liš neurčité.

Lidé chtějí akci, a nebo aspoň šprým.

Po našem to bude: „Na začátku byl čin!“ (Goethe 2004, 25)

Radek Malý:

Zde: na počátku bylo slovo.

S tím nesouhlasím. Já mám dojem,

že na začátku byl spiš pojem,

smysl, jenž označuje dílo.

Kde ty však zůstala jsi, sílo?

Dál hledám. Náhle zmizí stín.

Píšu: byl na začátku čin. (Goethe 2018, 98)

\section{Schlussbemerkung}

Fischers Übersetzung des Faust wird, wie oben erwähnt, als kanonisch erachtet wobei zu bedenken ist, dass dies im tschechischen Umfeld eigentlich eine Ausnahme darstellt. Deshalb ist es interessant, zu sehen, wie Jiří Levý dieses Phänomen der „Über- 
setzung als Klassiker" betrachtet. Langfristig schließt er die Möglichkeit, dass Übersetzungen als Klassiker gelten, aus, denn die Tatsache, dass eine Übersetzung in die Kategorie der „reproduktiven Künste" fällt, macht aus dieser Kunstform eine vergängliche Erscheinung: „Ebensowenig wie eine definitive und ein für allemal gültige schauspielerische Hamlet-Auffassung gibt es eine definitive übersetzerische Konzeption." (Levý 1969, 78) In der allgemeinen Argumentationslinie kann man Levý bei dieser Behauptung zustimmen: jedwedes abgeleitete Werk als endgültige und universelle Interpretation zu betrachten, wäre ziemlich problematisch.

In Hinblick auf die Übersetzung eines Theatertextes - und hier kommt die Problematik der aktuellen Faust-Übersetzung ins Spiel - ist Levýs Analogie zur Schauspielkunst beachtenswert: Der übersetzte Text ist, als literarisches Werk in unveränderlicher Gestalt fixiert, jedoch wird er in der Praxis, auf der Bühne, in unterschiedlichen Aufführungen jedes Mal neu realisiert, und somit auch jedes Mal anders. Dennoch kann sich eine konkrete Inszenierung eines Theaterstücks als „klassisch“ oder „unübertreffbar“ in das Unterbewusste einschreiben. Das Problem liegt also darin, dass Levý die „klassische“ Übersetzung mit der „definitiven“ Übersetzung gleichsetzt.

Wenn man allerdings von Levýs Analogie mit der Schauspielkunst ausgeht, bietet sich eine interessante Parallele zu dem unkonventionellen Zugang, der bei der aktuellen Übersetzung des Faust für das Národní divadlo gewählt wurde. Auch dieser ist der Versuch einer Art „Umsetzung“ des Faust, eine bestimmte Lesart des Regieteams - und nicht des Übersetzers, der den Text in diesem Fall nicht im selben Ausmaß interpretierte, wie es bei Übersetzungen sonst üblich ist. Die Dramaturgin Marta Ljubková äußert sich in ihrem Aufsatz O textové verzi našeho Fausta (dt. „Über die Textversion unseres Faust“) folgendermaßen:

Diese Version wird zu Recht als Inszenierungsversion bezeichnet, denn sie entstand nur für unsere Inszenierung. Alle Streichungen und Bearbeitungen, die wir in der Übersetzung von Fischer vorgenommen haben (unter Berücksichtigung von Goethes Original sowie der englischen Übersetzung) hat der Übersetzer Radek Malý später in unsere Version eingearbeitet. Wenn Sie also diesen Faust lesen, halten sie ein Extrakt des ursprünglichen Werks von Goethe in den Händen. Oder noch besser - unseren Versuch einer Dramatisierung des Faust. Falls Sie sich mit der kompletten Version vertraut machen wollen, nehmen Sie am besten Leseurlaub. Es wird sich auszahlen - auch wenn es nur schwer inszenierbar ist ... (Ljubková 2018, 62-63).

Vieles von dem Textmaterial, das für die aktuelle Inszenierung übersetzt wurde, wurde schließlich, aus verständlichen Gründen, nicht verwendet. Ich glaube deshalb, dass ich, mit etwas Abstand, jedoch in absehbarer Zeit, dazu kommen werde, eine Übersetzung zu erstellen, die in ihrer Struktur dem Original näherkommt. In diesem Moment kann man der Inszenierung des Faust im Stavovské divadlo nur wünschen, dass sie das zeitgenössische Publikum anspricht. Leistet die Sprache des Texts und dessen Sprechbarkeit dazu einen Beitrag, so erfüllt die Übersetzung ihren Zweck. 


\section{LITERATUR}

\section{Primärliteratur}

Goethe, Johann Wolfgang: Faust, Leipzig: Reclam 2014.

Goethe, Johann Wolfgang: Faust, přeložil Josef Jiř́ Kolár, Praha: Kober 1863.

Goethe, Johann Wolfgang: Faust, přeložil František Vlček, Praha: Höfer a Klouček 1890.

Goethe, Johann Wolfgang: Faust, přeložil Jaroslav Vrchlický, Praha: Otto 1927.

Goethe, Johann Wolfgang: Faust, přeložil Otokar Fischer, Praha: Státní nakladatelství krásné literatury, hudby a umění 1957.

Goethe, Johann Wolfgang: Faust, přeložil Karel Kraus, Praha: Národní divadlo 1997.

Goethe, Johann Wolfgang: Faust, přeložila Olga Mašková, Praha: Galén 2015.

Goethe, Johann Wolfgang: Faust, přeložil Petr Bouř, doktorfaust.cz 2004.

Goethe, Johann Wolfgang: Faust, přeložil Petr Bouř, doktorfaust.cz 2015.

Goethe, Johann Wolfgang: Faust, přeložil Radek Malý, Praha: Národní divadlo 2018.

\section{Sekundärliteratur}

Bouř, Petr: Goethův Faust aktuálně. Neviditelný pes, 2016. Online unter: http://neviditelnypes.lidovky.cz /literatura-goethuv-faust-aktualne-dtn-/p_kultura.aspx?c=A160406_213051_p_kultura_wag [5. 5. 2018].

Bratránek, František Tomáš: Výklad Goethova Fausta, přeložil Jaromír Loužil, Praha: Odeon 1957.

Fischer, Otokar: Literární studie a stati I, Praha: Odeon 1983.

Grebeníčková, Růžena (ed.): Kniha o Faustovi, překlady Jindřich Pokorný, Praha: Mladá fronta 1982.

Jirát, Vojtěch: Dva překlady Fausta. Rozbor slohu Jaroslava Vrchlického a Otokara Fischera, Praha: Fr. Borový 1930.

Just, Vladimír: Faust jako stav zadlužení. Desetkrát o Faustovi, pokaždé jinak, Praha: Karolinum 2014.

Levý, Jiř́: České teorie překladu: vývoj překladatelských teorií a metod v české literatuře: Sv. 1, Praha: Ivo Železný 1996.

Levý, Jiř́: Umění prekladu, Praha: Miroslav Pošta - Apostrof 2012.

Levý, Jiř́: Die literarische Übersetzung. Theorie einer Kunstgattung. Aus dem Tschechischen von Walter Schamschula. Frankfurt am Main: Athenäum 1969.

Ljubková, Marta: O textové verzi našeho Fausta, in Goethe, Johann Wolfgang: Faust, přeložil Radek Malý, Praha: Národní divadlo 2018, S. 60-63.

Potužil, Zdeněk - Tučková, Dana: Ediční poznámka, in: Goethe, Johann Wolfgang: Faust, přeložila Olga Mašková, Praha: Galén 2015, S. 297-298.

Stromšík, Jiří: Poznámky k novějším překladům Fausta, in: Souvislosti: revue pro křestanství a kultu$r u, 9 / 2,1998$, S. 52-58.

\section{RESUMÉ}

Studie se zaměřuje na drama Faust J. W. Goetha a její překladatelská specifika a nároky. Sleduje historii překládání Fausta do češtiny a komentuje autorův vlastní překladatelský př́istup.

Doc. Mgr. Radek Malý, Ph.D.

Katedra žurnalistiky, Institut komunikačních studií a žurnalistiky, Fakulta sociálních věd, Univerzita Karlova

radek.maly@cuni.fsv.cz 